\title{
Researching the Impact of Student Mentoring in the Community
}

\author{
Alethea Melling, Ridwanah Gurjee* \\ The School of Education and Social Science, University of Central Lancashire, UK \\ *Corresponding Author: amelling@uclan.ac.uk(Alethea Melling), rgurjee@uclan.ac.uk(Ridwanah Gurjee)
}

\begin{abstract}
This research explores the impact of mentoring relationships on student mentors at the University of Central Lancashire (UCLan). More specifically, it looks at student experiences, personal and professional development from mentoring in the community over one academic year. This interpretive, methodological approach incorporated both qualitative and quantitative methods in order to draw comparisons and detailed insight into the interactions of all parties involved in the mentoring programme, including the mentor, the mentee and the community organisation. The findings revealed that mentors receive an 'invisible gift' that is not formally acknowledged. The 'gift' is manifested as key skills for lifelong learning and employability. Also, the findings highlighted that mentoring has a significant impact on the mentee regarding enhancing confidence, self esteem, skill development and engagement in pro-social behavior; thus, identifying 'hard' and 'soft' outcomes from UCLan Students engaging with the community in a mentoring capacity. This research concludes that the mentoring process utilises a 'mentee-centred approach.' A balance of both 'instrumental and 'expressive' processes in order to support, encourage and guide mentees to achieve their full potential.
\end{abstract}

Keywords Mentoring, Community, Lifelong Learning, Employability

\section{Introduction}

The University of Central Lancashire, Centre for Volunteering and Community Leadership (CVCL) has an extensive portfolio of volunteering, mentoring and community engagement, through the development of extremely innovative, youth-led projects. One of the key functions is to encourage mentoring and community engagement, raise the aspirations of our students and increase access to opportunities for education and employment. The mission of $\mathrm{CVCL}$ is to 'Empower, Engage and Enable' students in the direct delivery of Copyright $(\underset{2}{2013}$ Horizon Research Publishing community projects. A particular project that is the focus of this research is the case study of UCLan Student Mentoring in the Community.

This research and exploration into the impact of UCLan Student Mentoring in the Community highlights the value of the project and provide evidence of good practice within the School of Education and Social Science, UCLan.

The key aim of this project is to explore two key questions:

- Is there an impact on the student's personal and skill development? If so, how?

- To what extent do students find the process beneficial?

This study was carried out over one academic year with 19 students from the School of Education and Social Science that have been engaged in mentoring projects in the community with CVCL. Out of these 19 students, 7 completed a Key Skills Analysis, before and after the mentoring project. The reflective portfolios of 3 students was analysed and 9 students took part in focus group discussions made up of semi-structured questions.

There were also 24 mentees from community mentoring projects who completed a questionnaire as an evaluation tool at the end of their mentoring experience. Finally, I carried out 2 semi-structured interviews with Project Co-ordinators from community organisations that had student involvement.

\section{Literature Review of Mentoring}

Looking at the history of mentoring, Grossman and Garry (1997) found that mentoring is a promising approach to enriching the lives of young people and particularly those from disadvantaged backgrounds and at risk of offending with a positive role model. Their research explores early concepts when, back in 1904 Ernest K. Coulter founded a project that used the idea of 'big brothers' to reach out to young people who were in need of guidance, support and positive adult role models. This resulted in the Big Brothers and Big Sisters of America and still continues to operate till this day as one of the largest mentoring programs across the globe. An 18 month evaluation of this program found that 
$46 \%$ of young people mentored were less likely to get themselves involved in drug use, $27 \%$ were less likely to initiate alcohol use and were more likely to improve their grades at school and enhance their relationships with family and friends. Volunteers and mentors come from all walks of life with the aim of being a caring adult and making a difference to the lives of young people. Grossman and Gary (1997) concluded that this research presented clear evidence that mentoring programs result in a wide range of tangible benefits. Thus, the aim of this research has identifed the value of UCLan Student Mentoring in the Community and provided evidence of the effectiveness of this project.

In the UK, mentoring was identified as a social inclusion strategy and adopted by the Labour Government in 1997 as a way of raising standards and attainment in schools following the failing post-Thatcher educational system (Gardiner, 2008). This resulted in initiatives such as the National Mentoring Pilot Project where UCLan undergraduates were trained and deployed into Education Action Zone (EAZ) Schools across Lancashire.

Over the past decade, much research has then followed in order to understand the concept of mentoring in more detail. Researchers, such as, Kamvounias, McGrath and Yip (2008) studied the reflections of mentees on their participation of a formal mentoring program. The research study by Kamvounias et al (2008) looked at a mentoring pilot program established at the University of Sydneyamongst the Faculty of Education and Social Work and the Faculty of Economics and Business. Following six months of the project, 28 participants wrote a reflective account of their experiences. A key finding from this research was the desire to give: Mentees were grateful for the Mentors commitment and for their time. Mentors also felt that they had received 'gifts' from their mentees in terms of changing the way they conduct themselves, acquiring enhanced knowledge and discovery of their wisdom that they had not been aware of. Another 'gift' that mentors reflected on receiving was the opportunity to be involved in the mentoring project, suggesting that obligation, reciprocating and gratitude are all interlinked to building 'dialogue' within the mentoring relationship. Gifts within this research, imply that Mentees give 'gifts' as a way of saying thank you for the mentoring support that they receive with many of these gifts being 'invisible' gifts that mentors are not aware of. Hence, the aim of this research has been to identify the possible benefits for mentors and explore the 'invisible gift' that mentees may be giving to student mentors. This concept is something that is generally overlooked in literature and in process evaluation; therefore the aim of this research was to add to the limited literature on the prospective benefits for student mentors.

\section{Impact of Mentoring}

A recent study examines the effectiveness of informal mentoring of football coaching on young people in schools and housing estates with high levels of deprivation. There was some evidence of the sports activities having an impact on the young people's behavior, enhancing their self-esteem and confidence (Rogers, 2011). There was also significant feedback about young people being able to identify their mentors and coaches as role models. However, there was no quantifiable measurement indicating this type of informal mentoring intervention reduced anti-social behaviour, increased self-esteem, enhanced school attendance or reduced truancy rates in the schools that were being studied by Rogers (2011). Yet, so many mentoring projects state that it is incredibly fulfilling to be a part of the transitional phases within a young person's life. Therefore, it is important to evidence the outcomes of UCLan Student Mentoring in the community using appropriate methodologies in order to highlight the impact of this initiative. Does mentoring really have the positive impact that so many mentoring projects suggest, or is the reality actually being concealed by 'assumed benefits?' Knowles and Parsons (2009) illustrate this when they carried out an evaluation of a formalised peer mentoring project. Their findings revealed that interviews and questionnaire data on 'liking' the initiative and 'perceptions' that it was good was telling a different story to the actual impact of mentoring on behavior and attendance. Consequently, the aim of this research is to provide a deeper understanding of the link between mentoring and impact.

On the other hand researchers, such as Bennett (2003) argue that although mentoring may be a useful intervention to adopt, it should not be used as a political distraction or pacifier with regard to addressing deep rooted social problems and underlying inequalities in society. He further argues that mentoring "is unlikely to find homes for the homeless, and while it may assist with skills in becoming "job-worthy", it will not create jobs in areas of high unemployment" Bennett (2003).

The ethos adopted by UCLan, CVCL and also supported by established social scientists such as Putnam (2000) portray that mentoring interventions simply should be seen as a means of allowing young people to enhance their social and personal skills, be able to reflect and learn from the process and accumulate social capital. Therefore, the aim of this research is to identify these aspects and highlight the impact of mentoring in the community regarding student personal and professional development.

\section{Approaches to Measuring Impact of Mentoring}

Researchers, such as, Deutsch and Spencer (2009) argue that in order to assess the quality of mentoring programs and mentor and mentee relationships it is important to understand the characteristics and processes involved in individual mentoring relationships. This research has looked at the psychosocial impact of mentoring and academic outcomes which could possibly be identified in student mentors in the community.

On the other hand, the gap in literature on mentoring, according to Rhodes and Dubois (2006) is largely due to the 
nature of mentoring and the difficulty to research such confidential, one-to-one, supportive formal relationships. A traditional mentoring relationship is largely an independent process where mentor and mentee are matched by the mentor co-ordinator and are left to build a connection with each other. Thus, only checking in with the mentoring project itself when specific support or information is required. The adherence to confidentiality in mentoring meetings means that it is not practical to observe mentoring pairs in order to research the impact of mentoring. Therefore, researchers have to rely on reflective accounts of mentoring experiences before and after the program in order to measure outcomes and look at the quality of mentoring relationships

Furthermore, Parra, DuBois, Neville, Pugh-Lilly and Pavineli (2002) carried out an investigation on a process-orientated model of mentoring, using mentoring relationship from the Big Brothers and Big Sisters mentoring program. The overall results found that self efficacy tested at the start of the relationship predicted that this will relate to greater contact time between mentor and mentee as well as more positive the experience and feelings of closeness within the relationship which in turn is more likely to achieve benefits from mentoring as well as the relationship would continue. Thus, this research will aim to establish whether confidence levels impacts on the mentoring relationship in anyway and add to the pedagogic literature of mentoring.

Furthermore, Deutsch and Spencer (2009) claim that observational research on mentoring is a challenging methodology to adopt when looking at the impact of mentoring and recommend interviews and open-ended surveys to gain perceptions of the quality of the mentoring. This suggestion is incorporated into the study of student mentors as focus groups and semi-structured interviews are adopted to gain perceptions of the impact of mentoring.

\section{Methodology}

This research adopts Interpretive Phenomenological Analysis (IPA) and narrative research which explores the subjective experiences of the mentors and mentees, for example, asking mentors 'what did you learn from being a mentor' and asking mentees 'what were the benefits for you to have a mentor?'(Fox, Martin and Green, 2007).

This position has methodological implications, for example, data collected needs to be from qualitative approaches to offer a deeper understanding of individual experiences, and also emphasise the importance of adopting reflexivity and acknowledging how ones own position as a researcher has an effect on the research process, findings and outcomes (Fox, Martin and Green, 2007).

Furthermore, Cousin (2009) suggests the use of triangulation as a way towards ensuring the trustworthiness and plausibility of the research process. Therefore, the methodology adopted in this research includes both, a qualitative and quantitative approach.

The methods adopted in this research include the following:

- Questionnaire - A questionnaire for Mentees was devised following research on an evaluation template of the Apprentice Mentoring Program (2007).

- Key Skills Analysis - An evaluation tool adopted from the 'Broadening Horizons Workbook,' piloted in UCLan in 2000-2002. This workbook was designed to compliment the National Record of Achievement(NRA), introduced in 1991 as a way of providing a national framework for summarising educational, employment and training experiences throughout life.

- Focus Group - To yield a collective view from student mentors.

- Reflective Portfolio - These are submitted as a formative assessment by students on the module at the end of the academic year and give a deeper insight into to the benefits of mentoring for the student.

- Interviews - Two individual, semi-structured interviews carried out with the mentor co-ordinators from an East Lancashire School and a youth leadership programme.

\section{Ethical Considerations}

This research made contact with Year 2 students currently studying BA (Hons) Community Leadership and completing the Mentoring in the Community module (VO2001) at Level 5 of the undergraduate degree programme. The students were informed of this research and consented to take part, a protocol outlined by Schostack (2002). The aspects of confidentiality and anonymity had been emphasized and made clear to the students who decide to participate.

The research also involved access to the mentees from community organisations that have been matched with the Student Mentor. These mentees were from various community setting, such as, young people in a school with special educational needs, young offenders, young people or adults in a care home or their peers from the university. Therefore, it was very important to ensure informed consent is obtained from each participant and parental consent is obtained for all those under 18 years old. In addition to this, as Cousins (2009) indicates, informed consent will be an ongoing stage where participants will be able to view transcripts and findings of the research.

The research also ensures compliance to data protection and all questionnaires and findings from participants will be stored in accordance to the university regulations.

An important aspect to consider prior to student involvement in Mentoring in the Community is the completion of an enhanced check by the Disclosure and Barring Service (DBS).This executive agency of the Home Office has been set up to ensure safer recruitment decisions and identify those people who may be unsuitable to work with children or vulnerable adults (Home Office, 2012). Thus, only those that are received as satisfactory were able 
to participate in this research and will compensate to some extent for the fact that the Mentees are vulnerable people.

\section{Techniques for Data Analysis}

The data for this research has been gathered using various methods. Subsequently, the process for data analysis of the qualitative data included categorising the data to identify themes and understand what is happening within the mentoring experience of the students. Following categorisation, as outlined by Campbell et al (2004) the final stage of data analysis included interrogating the data in response to the questions posed on the impact of mentoring on student personal and professional development as well as the benefits from the mentoring process. The interrogation of data includes descriptive claims in terms of gender, age and ethnicity as well as explanatory claims.

\section{Mentee Questionnaire}

The results from the mentee questionnaire revealed mentoring has a positive experience and that they felt respected, valued and important by their mentor as well as a good connection with them. On the other hand, significant differences of opinion have been identified between groups on whether the mentoring relationship has helped to make progress towards achieving personal goals and whether the experience has made a positive impact on personal development. Key statistical trends that have been identified were; Males felt positive that the experience has helped them to achieve their personal goals and make a positive impact towards their personal development compared to Females. These findings have been discussed in relation to the report of Nemanick (2000) who outlines the findings of Ragins and Cotton (1999). They identified gender based differences in outcomes from mentoring programmes with male mentors reporting a higher level of compensation compared to females.

Also, under 16 year old Mentees scored more highly compared to the other age brackets on the opportunity to volunteer to be a mentor in the future. The results indicate, as identified by Sibicky (1992) that young people are motivated to gain career related experience, future rewards and the need to achieve in comparison to older adults.

In addition to this, a pattern of older females opting to volunteer in later life in comparison to males also emerged from the findings, highlighting a gender difference which is explained by Gilligan (1982) as a difference in moral reasoning between males and females.

Furthermore, mentees from an Indian ethnic group, particularly Indian Females and Indian Males were more inclined to agree on becoming a volunteer as a mentor in the future. The differences maybe explained using the Human Capital Theory by Wilson (2000), suggesting that lower levels of education, income and occupational status among some ethnic groups may indicate they are less likely to volunteer.

\section{Key Skills Analysis BEFORE Mentoring}

The results revealed that mentors were most confident with the skill of working with others as a team through listening, understanding and respecting them, helping others to action plan as well as meet deadlines and also in terms of organising themselves and meeting deadlines (See Figure 1: Key Skills Analysis Before Mentoring). The skill of working with others received the highest percentage at $69 \%$ then followed the key skill of Improving own Learning and Performance with $67 \%$ and Information Computer Technology (ICT) with 65\%. The key skill that received the lowest confidence rating from mentors was communication with $62 \%$.

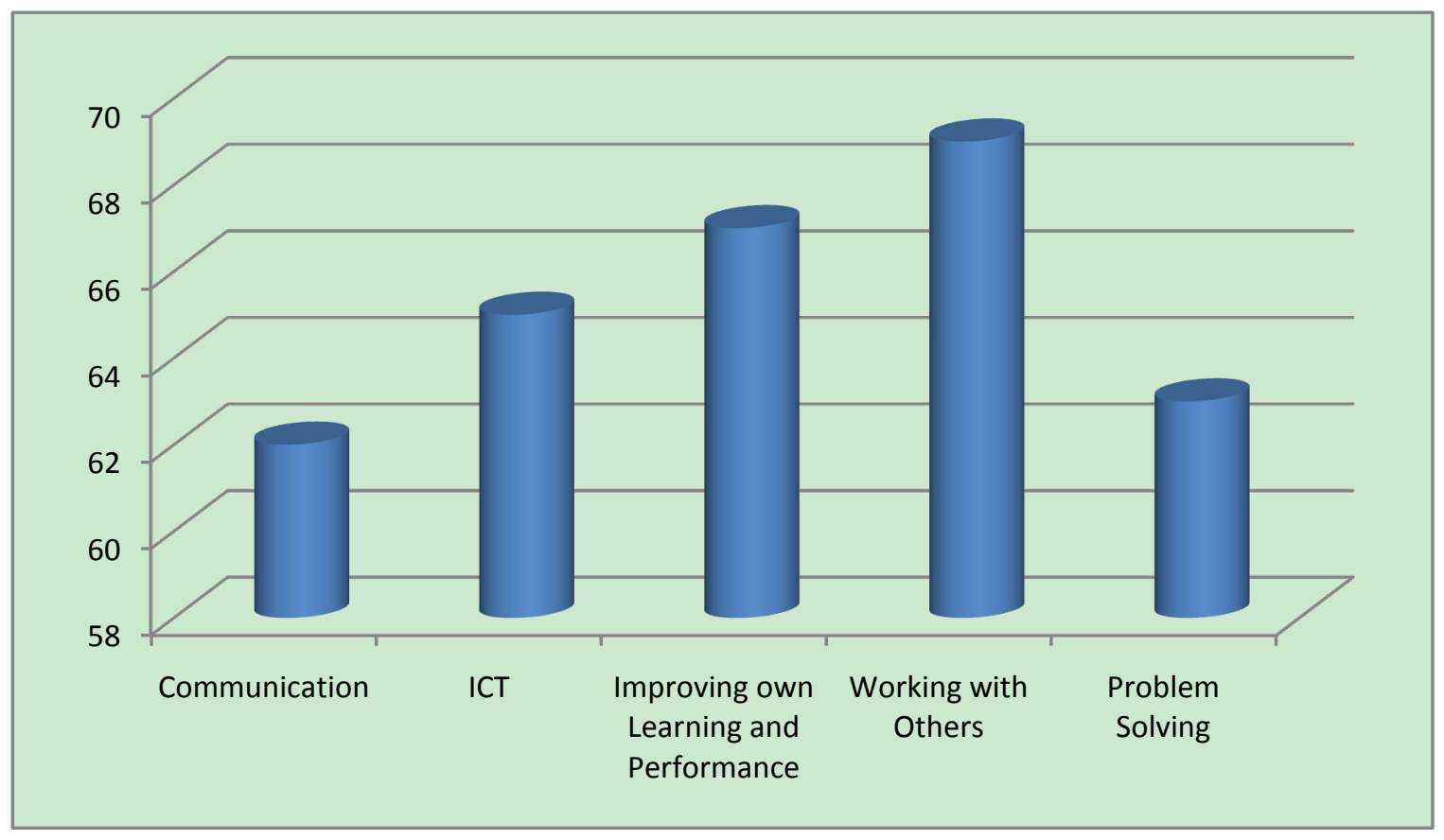

Figure 1. Key Skills Analysis BEFORE Mentoring 


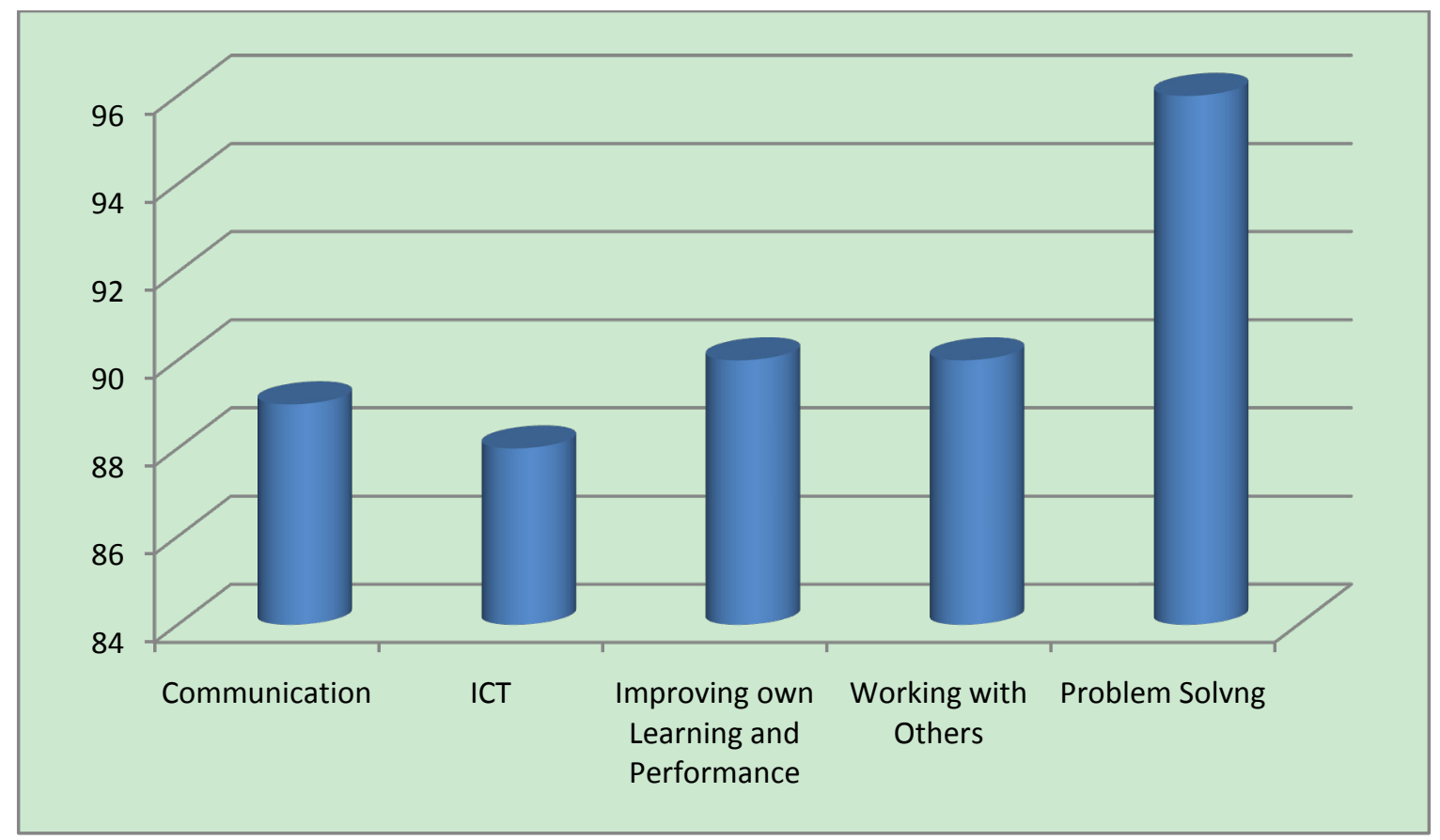

Figure 2. Key Skills Analysis AFTER Mentoring

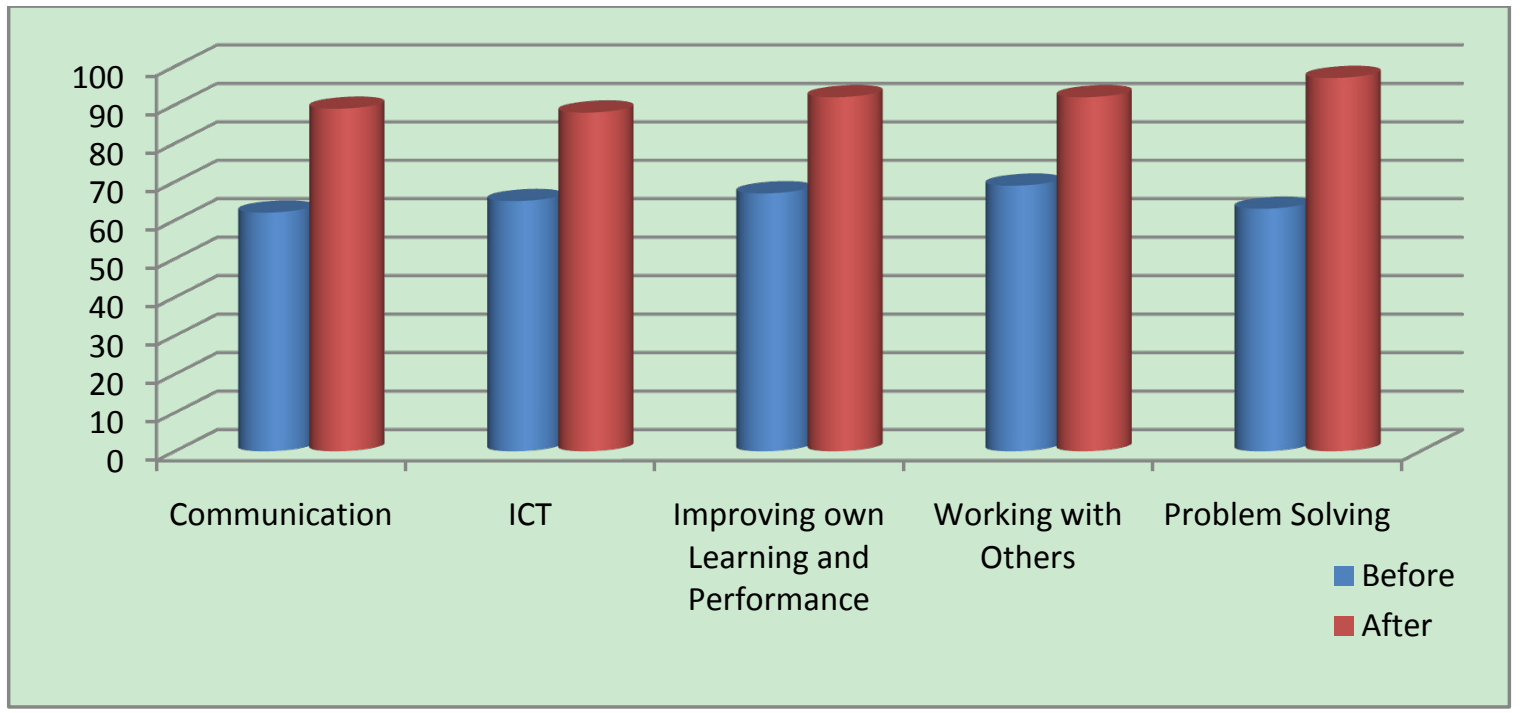

Figure 3. Comparison of Key Skills Analysis BEFORE and AFTER Mentoring

\section{Key Skills Analysis AFTER Mentoring}

The results revealed that the mentors confidence levels of three key skills, Improving own Learning and Performance, Working with Others and the key skill of Problem Solving all received percentage ratings above $90 \%$ with the highest percentage of $96 \%$ for the key skill of Problem Solving (See Figure 2: Key Skills Analysis After Mentoring). The skill that received the lowest confidence rating from mentors was the key skill of ICT with $88 \%$ and then followed Communication Skills with $89 \%$.

\section{Discussion}

At a first glance confidence levels on keys skills before and after mentoring, clearly highlight some significant differences in results (See Figure 3: Comparison of Key Skills Before and After Mentoring). The findings from the Key Skills Analysis reveal that confidence ratings in Communication Skills, ICT, Improving own Learning and Performance, Working with Others and Problem Solving have enhanced significantly following the student mentoring experience in the community. Therefore, clearly supporting the notion of a 'gift' that the mentor receives as identified by Kamvounias et al (2008:18).

Also, self-efficacy in this case grows from low levels to high, throughout the mentoring relationship which leads to 
positive outcomes. This contradicts Parra et al (2002) who claim that the high self-efficacy of mentors will lead to positive outcomes in the mentoring relationship, as many of the students received low confidence ratings before starting their formal mentoring relationship, particularly with regards to communication skills. As Clayden and Stein (2005) may categorise, the mentoring relationship had produced both 'soft' and 'hard' outcomes for themselves and their mentee. Thus, self-efficacy in this case grows from low levels to high, throughout the mentoring relationship which leads to positive outcomes.

\section{Focus Group \& Reflective Portfolios of Mentors}

The findings of the focus group and reflective portfolios highlight the fact that the Mentee is the driving force behind the mentoring sessions and the mentor will adopt a 'mentee-centred approach.' Thus, similar to Clayden and Stein (2005) there was no evidence of a simply instrumental model of mentoring used by the students which highlights the need to ensure a balance between the two dimensions.

The results have generally identified mentoring as a positive experience for the student mentors with some key areas of personal development that they will take with them in all aspects of their future life. The reflective portfolios have been an extremely useful tool to allow students to reflect on their personal development and the process of mentoring as proposed by Putnam (2000). The students have been given the opportunity to be able to analyse and conceptualise their aims and objectives of getting involved in the mentoring projects in the first place and think about the benefits they want to gain through reflection and portfolio development and engagement in group discussions. The general aim is that they identify learning from the mentoring process and this seems to have been the case as they have highlighted a number of key skills ranging from communication skills, team building, problem solving, leadership skills and many more.

Furthermore, Knowles and Parsons (2009) research findings highlighted that mentoring is generally attributed in a positive way and perceived as 'good,' however there was no evidence of impact of mentoring on behaviour and attendance. This is a different story in this research as the results have identified that there were many positive attributes to mentoring, such as 'good' 'enjoyable' ' massively beneficial' as well as outlining some 'hard' and 'soft' outcomes on positive behaviour, attitudes, and particularly personal and professional development following the mentoring experience.

\section{Semi-Structured Interviews}

The mentoring organisation involved with working with young people in the community or in a school establishment aimed to enhance leadership skills for the young people and empowering them, enhancing their potential, helping those in need of the support and making a difference in some way.
"Its about giving them guidance, empowering them and being a role model for our pupils"

"Empowering the young people to develop leadership skills and also a way to sort of, build their confidence to better the community that they live in"

Furthermore, there were many outcomes identified for the mentee. As illustrated by Clayden and Stein (2005) there were a lot more 'hard' outcomes identified for the mentee with the co-ordinators both commenting on the visible difference that they see in the mentees following the mentoring relationship:

"The recent peer leadership and mentoring program with young people that have been excluded from mainstream school has been fantastic....teachers have said they have actually seen a difference in the young people, they are concentrating more in class and participating in activities where as they really struggled to engage these young people before"

"We as youth workers for the school have seen a difference in the young people from when they first start the project and then at the end. Start and finish seems different, they seem to be talking more, are more organised and wanting to do more projects with Youth side."

On the other hand some soft outcomes of confidence and self-esteem that was also evident, such as:

"It really does challenge the young and it definitely builds on their self esteem and gives them confidence"

\section{Conclusions}

This empirical research has provided clear significant evidence which highlights the importance of UCLan student mentoring in the community to enhance the personal and professional development of students. The benefits that they gain from the experience and the skills that are developed can be transferred in future employment and all walks of life.

Overall, the results from the mentee questionnaire revealed mentoring has been a positive experience and that they have felt respected, valued and important by their mentor as well as felt a good connection with them. On the other hand, significant differences of opinion have been identified between groups on whether the mentoring relationship has helped to make progress towards achieving personal goals and whether the experience has made a positive impact on personal development.

Key statistical trends support the findings of Ragins and Cotton (1999) cited in Nemanick (2000) who identified gender based differences in outcomes from mentoring programmes with male mentors reporting a higher level of compensation compared to females.Also, as pointed out by Sibicky (1992) under 16 year oldsare motivated to gain career related experience, future rewards and the need to achieve in comparison to older adults.In addition to this, a pattern highlighting gender differences ofvolunteering in later life which is explained by Gilligan (1982) as a 
difference in moral reasoning between males and females.

Furthermore, mentees from an Indian ethnic group, particularly Indian Females and Indian Males were more inclined to agree on becoming a volunteer as a mentor in the future. The differences maybe explained using the Human Capital Theory by Wilson (2000), suggesting that lower levels of education, income and occupational status among some ethnic groups may indicate they are less likely to volunteer.

The findings from the Key Skills Anaylsis reveal that confidence ratings in Communication Skills, ICT, Improving own Learning and Performance, Working with Others and Problem Solving have enhanced significantly following the student mentoring experience in the community. Therefore, clearly supporting the notion of a 'gift' that the mentor receives as identified by Kamvouniaset al (2008).

Also, self-efficacy in this case grows from low levels to high, throughout the mentoring relationship which leads to positive outcomes, contradicting the findings of Parra et al (2002) that the high self-efficacy of mentors leads to positive outcomes in the mentoring relationship

The findings of the focus group and reflective portfolios highlight the fact that the Mentee is the driving force behind the mentoring sessions and the mentor will adopt a 'mentee-centred approach.' Thus, similar to Clayden and Stein (2005) there was no evidence of a simply instrumental model of mentoring used by the students which highlights the need to ensure a balance between the two dimensions.

The results have generally identified mentoring as a positive experience for the student mentors with some key areas of personal development that they will take with them in all aspects of their future life. The reflective portfolios have been an extremely useful tool to allow students to reflect on their personal development and the process of mentoring as proposed by Putnam (2000). The students have been given the opportunity to be able to analyse and conceptualise their aims and objectives of getting involved in the mentoring projects in the first place and think about the benefits they want to gain through reflection and portfolio development and engagement in group discussions. The general aim is that they identify learning from the mentoring process and this seems to have been the case as they have highlighted a number of key skills ranging from communication skills, team building, problem solving, leadership skills and many more.

Furthermore, Knowles and Parsons (2009) research findings highlighted that mentoring is generally attributed in a positive way and perceived as 'good,' however there was no evidence of impact of mentoring on behaviour and attendance. This is a different story in this research as the results have identified that there were many positive attributes to mentoring, such as 'good' 'enjoyable' ' massively beneficial' as well as outlining some 'hard' and 'soft' outcomes on positive behaviour, attitudes, and particularly personal and professional development following the mentoring experience.
This was further supported by the semi-structured interviews with mentor co-ordinators which highlighted both, 'hard' and 'soft' outcomes as proposed by Clayden and Stein (2005). Mentees were identified by their mentor co-ordinators as having enhanced self-esteem and developed personal qualities as well clearly demonstrating visible changes in behavior and attitude by engaging in extra curricular activities.

In addition to this, another key aspect from the study by Clayden and Stein (2005) also shared by the UCLan students is how the mentor training was extremely valuable to them and supported them in their mentoring relationship. However, it could also be important to incorporate this aspect of 'instrumental' and 'expressive' mentoring styles into the training sessions in order for them to acknowledge and characterise some of the approaches that they are adopting.

This applied learning environment followed by reflective reviews and portfolio development are central to CVCL and provides students with the opportunity to acknowledge the benefits, more often than not they are 'invisible' benefits, that they reap from practical experience.

\section{REFERENCES}

Apprentice Mentoring Program (2007).Evaluation Templates: Apprentice Mentoring Program. Last accessed online on 8 November 2012 at URL

http://www.coaa.ab.ca/Portals/0/Downloads/BP\%20Workforce/Ap pendix-E-Evaluation-templates.doc

Bennett, C. (2003). Mentoring Youth: Trend and Tradition.British Journal of Guidance and Counseling. Volume 31, Issue No 1, Pages 63-75.

Clayden, J. and Stein, M. (2005). Mentoring Young People Leaving Care -'Someone for me.'Joseph Rowntree Foundation: York.

Cousin, G. (2009). Researching Learning in Higher Education: An Introduction to Contemporary Methods and Approaches. Routledge Taylor and Francis Group: New York and London.

Deutsch, N. L. and Spencer, R. (2009). New Directions for Youth Development, Chapter 3 - Capturing the magic: Assessing the Quality of Youth Mentoring Relationships. Wiley InterScience: Tokyo.

DuBois, D. L. Doolittle, F. Yates, B. T. Silverthorn, N. and Kraemer-Tebes, J.(2006). Research Methodology and Youth Mentoring.Journal of Community Psychology. Volume 34, Issue 6, Pages 657-676.

DuBois, D. L.Portillo, N. Rhodes, J. Silverthorn, N and Valentine, J. (2011). How effective are mentoring programs for youth? A systematic assessment of the evidence.Psychological Science in the Public Interest. Volume 12, Issue 2, Pages 57-91.

Fox, M. Martin, P. and Green, G. (2007). Doing Practitioner Research. Sage Publications Ltd: London.

Gardiner, C. E. (2008). Mentoring: Towards an improved Professional Friendship. The University of Birmingham, Department of Sociology: Birmingham. 
Gilligan, C. (1982). In a Different Voice: Psychological Theory and Women's Development. Harvard University Press: Cambridge.

Grossman, J. B. and Garry, E. M. (1997).Mentoring - A Proven Delinquency Prevention Strategy. Office of Juvenile Justice and Delinquency Prevention, US Department of Justice: Washington DC.

Home Office (2012).About the Criminal Records Bureau. Last accessed online on 13 August 2012 at URL http://www.homeoffice.gov.uk/agencies-public-bodies/crb/about-c $\mathrm{rb} /$

Kamvounias, P. McGrath-Champ, S.and Yip, J. (2008). 'Gifts' in mentoring: Mentees reflections on an academic development program. International Journal for Academic Development.Volume 13, Issue No. 1, Pages 17-25.

Knowles, C and Parsons, C. (2009). Evaluating a formalized peer mentoring program: A student voice and impact audit. Pastoral Care in Education. Volume 27, Issue No. 3, Pages 205-218.

Little, C. A.Kearney, K. L. and Britner, P. A. (2010). Mentorship and its Influences: Students Self Concept and Perceptions of Mentoring Relationships in a Summer Mentorship Program for Talented Adolescents. Roeper Review - The Roeper Institute. Volume 32, Pages 189-199.

Manning, L. (2010). Gender and Religious Differences Associated with Volunteering in Later Life. Journal of Women and Aging. Volume: 22, Issue No: 2, Pages 125-135.

Melling, A. and Jones, P. J. (2001). Broadening and Widening Horizons: DfEE Key Skills Workbooks as a tool of qualitative research in the mentoring and tracking of widening participation initiatives.Department of Education and Social Science, University of Central Lancashire: Preston.

Nemanick, R. C. (2000). Comparing Formal and Informal Mentors: Does Type Make a Difference. Academy of Management
Executive.St Louis University: United States of America.

Newburn, T. and Shiner, M. (2006).Young People Mentoring and Social Exclusion. Youth Justice. Volume: 6, Issue: 1, Pages 23-41.

Parra, DuBois, D. L. Neville, H. A. Pugh-Lilly, A. O. and Pavineli, N. (2002). Mentoring Relationships for Youth: Investigation of a Process-Oriented Model. Journal of Community Psychology. Volume 30, Issue 4, Pages 367-388.

Philip, K. (2008). Youth Mentoring - A Case for Treatment. Youth and Policy. Volume: 99, Pages 17-33.

Putman, R. (2000). Bowling Alone.New York: Touchstone.

Rhodes, J. E. (2002). Stand by Me: The Risk and Rewards of Mentoring Todays Youth. Harvard University Press, Cambridge.

Rhodes, J. E and DuBois, D. L. (2006). Understanding and Facilitating the Youth Mentoring Movement.Social Policy Report.Volume: 20, Issue: 3, Pages 3-19.

Rogers, R. (2011). Evaluating community-based interventions for young people: measuring the impact of informal mentoring.Journal of Poverty and Social Justice. Volume 19, Issue No 2, Pages $159-168$.

Schostack, J. F. (2006). Interviewing and Representation in Qualitative Research Projects. Open University Press: Buckingham, UK.

Sibicky, M. (1992). Motivation Underlying Volunteerism: Differences and Similarities between Student and Senior Citizen Volunteers. Southeastern Psychological Association, Knoxville.

Smithson, J. (2000). Using and analyzing focus groups: Limitations and Possibilities. International Journal of Social Research Methodology. Volume: 3, Issue: 2, Pages 103-119.

Wilson, J. (2000). Volunteering. Annual Sociology Review. Volume: 26, Pages 215-240. 